\title{
Estratégias complementares ao ensino de Química
}

\author{
Complementary strategies for teaching Chemistry \\ Estrategias complementarias para la enseñanza de la Química
}

Recebido: 04/01/2021 | Revisado: 04/01/2021 | Aceito: 05/01/2021 | Publicado: 07/01/2021

Luana Kayena Alves da Silva

ORCID: https://orcid.org/0000-0002-3792-1028

Instituto Federal de Educação, Ciência e Tecnologia de Minas Gerais, Brasil E-mail: 1kayena@gmail.com

Maicon Douglas Gomes da Silva

ORCID: https://orcid.org/0000-0001-7384-1335

Instituto Federal de Educação, Ciência e Tecnologia de Minas Gerais, Brasil

E-mail: maycomsilva986@outlook.com

Priscila Ferreira de Sales

ORCID: https://orcid.org/0000-0002-9313-9575

Centro Federal de Educação Tecnológica de Minas Gerais, Brasil

E-mail: priscila.sales@cefetmg.br

Phelipe Góis

ORCID: https://orcid.org/0000-0001-6021-2230 Universidade Federal de Lavras, Brasil

E-mail: pjgois@yahoo.com.br

Wilton José Ferreira

ORCID: https://orcid.org/0000-0002-6018-5751

Escola Estadual João Batista de Carvalho, Brasil

E-mail: wiltonquimica@yahoo.com.br

\begin{abstract}
Resumo
Este trabalho consiste de um relato de experiência de um projeto de extensão que foi desenvolvido com o objetivo de aprimorar a disciplina de Química nas turmas de segundo ano (Ensino Médio e EJA) das Escolas Estaduais de Bambuí, Minas Gerais. Para atingir tal objetivo, a equipe buscou utilizar diferentes estratégias didático-pedagógicas. Enquanto em uma das escolas foi trabalhado o Jogo "Quente ou Frio?" na abordagem do conteúdo de Termoquímica, em outra escola buscou-se empregar a atividade experimental "Solubilidade do $\mathrm{CO}_{2}$ no refrigerante- efeito da pressão" e textos de contextualização relacionados aos conteúdos de soluções e solubilidade. Para estes últimos conteúdos foram propostas atividades compostas de oito questões objetivas. A partir dos resultados obtidos, foi possível verificar que o jogo didático contribuiu para o diagnóstico de problemas relacionados ao conteúdo da temática envolvida, bem como permitiu motivar os estudantes durante a realização da atividade proposta, criando condições de novas formas de pensamento. A experimentação foi considerada como um recurso didático-pedagógico favorecedor da consolidação do ensino, já que os conceitos a ela associados obtiveram mais êxito na análise quantitativa das atividades propostas. Por fim verificou-se que a inserção de textos complementares vinculados ao cotidiano contribuiu para a formação de cidadãos críticos, capazes de atuarem em situações reais. Por meio da análise dos resultados obtidos, os participantes da equipe de extensão acreditam que o projeto motivou os docentes em sua prática e os estudantes em suas preconcepções.
\end{abstract}

Palavras-chave: Jogo didático; Experimentação; Contextualização.

\begin{abstract}
This work consists of an experience report of an extension project that was developed with the objective of improving the discipline of Chemistry in the second year classes (High School and EJA) of the State Schools of Bambuí, Minas Gerais. To achieve this goal, the team sought to use different didactic-pedagogical strategies. While in one of the schools the game "Hot or Cold?" in the approach to the thermochemistry content, in another school we sought to employ the experimental activity " $\mathrm{CO}_{2}$ solubility in the refrigerant- pressure effect" and contextualization texts related to the contents of solutions and solubility. For these latter contents, activities were proposed, consisting of eight objective questions. From the results obtained, it was possible to verify that the didactic game contributed to the diagnosis of problems related to the content of the theme involved, as well as to motivate students during the performance of the proposed activity, creating conditions for new ways of thinking. Experimentation was considered as a didactic-pedagogical resource that favors the consolidation of teaching, since the concepts associated with it were more successful in the quantitative analysis of the proposed activities. Finally, it was found that the insertion of complementary texts linked to daily life contributed to the formation of critical citizens, capable of acting in real situations. Through the analysis of the results obtained, the participants of the extension team believe that the project motivated the teachers in their practice and the students in their preconceptions.
\end{abstract}

Keywords: Educational game; Experimentation; Contextualization. 


\begin{abstract}
Resumen
Este trabajo consiste en un informe de experiencia de un proyecto de extensión que se desarrolló con el objetivo de mejorar la disciplina de la Química en las clases de segundo año (High School y EJA) de las Escuelas Estatales de Bambuí, Minas Gerais. Para lograr este objetivo, el equipo buscó utilizar diferentes estrategias didáctico-pedagógicas. Mientras en una de las escuelas el juego "Hot or Cold?" En el enfoque del contenido termoquímico, en otra escuela buscamos emplear la actividad experimental "Solubilidad de $\mathrm{CO}_{2}$ en el efecto de presión del refrigerante" y textos de contextualización relacionados con el contenido de soluciones y solubilidad. Para estos últimos contenidos, se propusieron actividades que constan de ocho preguntas objetivas. A partir de los resultados obtenidos, fue posible verificar que el juego didáctico contribuyó al diagnóstico de problemas relacionados con el contenido del tema involucrado, así como a motivar a los estudiantes durante la realización de la actividad propuesta, creando condiciones para nuevas formas de pensar. La experimentación se consideró como un recurso didáctico-pedagógico que favorece la consolidación de la enseñanza, ya que los conceptos asociados a ella tuvieron más éxito en el análisis cuantitativo de las actividades propuestas. Finalmente, se encontró que la inserción de textos complementarios vinculados a la vida cotidiana contribuyó a la formación de ciudadanos críticos, capaces de actuar en situaciones reales. A través del análisis de los resultados obtenidos, los participantes del equipo de extensión creen que el proyecto motivó a los maestros en su práctica y a los estudiantes en sus ideas preconcebidas.
\end{abstract}

Palabras clave: Juego educativo; Experimentación; Contextualización.

\title{
1. Introdução
}

Em todas as esferas governamentais, a disciplina de Química é trabalhada na maioria das vezes de forma tradicional, na qual se verifica um ensino teórico e deficiente, pautado na memorização de conceitos, fórmulas e equações, tornando-se pouco atraente para os estudantes, já que as aulas são ministradas de forma descontextualizada e discrepante do cotidiano (Arroio et al., 2006).

Nesse sentido são reportadas várias discussões levando em consideração a busca por recursos didáticos para serem utilizados em sala de aula, que contribuam para a aprendizagem significativa dos estudantes e sejam instrumentos de motivação na elaboração de aulas pelos professores da área.

Sendo assim, a atividade do docente deve transcender o simples ato de ministrar aulas, visto que as exigências quanto ao que o professor precisa "saber" e "saber fazer" tornaram-se tão grandes que se faz necessária a inserção de sua formação para assumir os desafios que se interpõem em suas práticas (Lima, 1996).

As atividades lúdicas são reportadas como práticas privilegiadas para a consolidação de uma educação que visa o desenvolvimento individual do estudante e sua possível atuação como cooperador na sociedade a qual pertence. Os instrumentos lúdicos são definidos como aqueles que atraem, motivam e estimulam o processo de construção do conhecimento, na medida em que propiciam meios para a indução do raciocínio e posterior reflexão. Pode-se ainda verificar a promoção do desenvolvimento cognitivo, físico, social e psicomotor, o que conduz a memorização mais adequada do conteúdo lecionado. Além disso, são desenvolvidas novas habilidades que se tornam necessárias às práticas educacionais da atualidade (Lima et al.,2018).

De acordo com abordagens relatadas na literatura, os jogos didáticos proporcionam uma metodologia inovadora, atraente, prazerosa e interessante, sendo considerados como um tipo de atividade lúdica que deve também apresentar um caráter educativo que vincule as várias dimensões do estudante, tais como a afetividade e o trabalho em grupo (Cunha, 2004).

O jogo lúdico propicia a diversão e colabora na função educativa, o que de modo geral, é um elemento de diversão que auxilia na formação de conceitos, sendo a distinção de um comum (Afonso et al., 2019).

Vale a pena salientar o emprego desse recurso didático-pedagógico na abordagem de conteúdos vinculados à temática de Termoquímica, uma vez que está inserida na maioria dos conteúdos programáticos de Química do segundo ano do Ensino Médio, no qual se foca os objetivos desse trabalho.

No trabalho desenvolvido por Soares \& Cavalheiro (2016), o jogo de tabuleiro "Ludo" foi empregado como instrumento de aprendizagem sobre os conceitos ligados à Termoquímica. De acordo com os autores, esse jogo tinha por objetivo iniciar o aluno ao conceito de variação energética nas transformações químicas, citando, por exemplo, a variação de 
entalpia $(\Delta \mathrm{H})$. Foi revelado que $95 \%$ deles estavam envolvidos com a atividade, o que o torna uma proposta alternativa de ensino.

Já Gonçalves (2016), utilizou o lúdico para ensinar Termoquímica a alunos do segundo ano do Ensino Médio. A metodologia utilizada incluiu o emprego de uma atividade lúdica com "cartas alimentares" sobre perguntas e respostas, sendo posteriormente proposto um exercício desafio aos estudantes. Foi constatado um melhor rendimento da turma analisada em comparação com outras em que não foi desenvolvida a sequência didática.

Afonso e colaboradores (2019) abordaram essa temática através da aplicação do jogo "TermoQuiz". Durante o desenvolvimento do jogo, o professor supervisor e as bolsistas perceberam que os alunos se empenharam na atividade, não só por perceberem que essa era uma oportunidade para rever os conteúdos estudados, os quais demonstraram dificuldades de compreensão, como também para conseguirem os pontos avaliativos que os ajudariam na média do $4^{\circ}$ bimestre, o que para muitos, resultou na aprovação para um nível escolar mais avançado.

Não obstante, verifica-se que a experimentação é concebida como outra estratégia de ensino que possibilita a integração do estudante com o mundo externo, de modo que proporciona maior facilidade na interpretação e entendimento do mesmo, sendo cada vez mais empregada na prática docente (Cruz et al., 2014; Sousa et al., 2014).

De acordo com Oliveira e colaboradores (2010), quando utilizada corretamente contribui para: motivar os estudantes, possibilitar o desenvolvimento de trabalhos em grupo, induzir a tomada de decisões, estimular a criatividade, aprimorar a capacidade de observação, analisar dados e propor hipóteses para os fenômenos, aprender conceitos científicos, detectar e corrigir erros conceituais dos estudantes, compreender a natureza da ciência, associar ciência, tecnologia e sociedade por meio do desenvolvimento de habilidades manipulativas.

Por fim verifica-se que o emprego de textos complementares no ensino de Química é uma estratégia aplicável na compreensão dos conteúdos ministrados em sala de aula que apresenta influência positiva no relacionamento entre discentes e docentes. Em uma análise aprofundada da discussão dos textos é possível conhecer as noções dos estudantes, explorando suas dificuldades conceituais, o que possivelmente culminará em um desempenho mais adequado por relacionar a teoria com a prática (Lima \& Benarrosh, 2010).

Vale, entretanto salientar que essas novas propostas de trabalho apresentadas somente oportunizarão a interlocução de saberes, a socialização e o desenvolvimento pessoal, social e cognitivo se forem bem exploradas, sendo então avaliada a possibilidade de capacitação dos docentes na área (Lima \& Benarrosh, 2010).

É possível ainda inferir que a inserção de novas estratégias exige com que os professores atuem como mediadores que devem oferecer possibilidades de construção do conhecimento, respeitando as diversidades singulares (Lima \& Benarrosh, 2010).

Diante do que foi apresentado, esse trabalho tem por objetivo relatar experiências de um projeto de extensão que foi desenvolvido com a finalidade de se aplicar diferentes estratégias didático-pedagógicas (textos complementares, jogos didáticos e experimentação) para a aprendizagem significativa de Química em turmas do segundo ano (Ensino Médio e EJA) nas Escolas estaduais de Bambuí, Minas Gerais.

\section{Metodologia}

Conforme pode ser relatado, as pesquisas buscam produzir novos saberes para a sociedade (Pereira et al., 2018). Partindo desse pressuposto, o trabalho proposto constitui-se de um relato de experiência, de natureza qualitativa e quantitativa que foi desenvolvido com as turmas de segundo ano (Ensino Médio e EJA) das Escolas Estaduais localizadas na cidade de Bambuí- MG. A metodologia foi conduzida em etapas. 
A primeira consistiu de reuniões que abordavam as diferentes metodologias que seriam trabalhadas nas escolas contempladas pelo projeto. Essa etapa envolveu a discussão dos temas propostos, sendo considerada essencial para a contextualização do processo de ensino e aprendizagem mútuo, visto que os estudantes que compunham a equipe puderam explorar os conceitos que seriam abordados, indagar e contribuir com suas ideias, tornando-os sujeitos ativos nas escolas.

A segunda etapa consistiu da capacitação dos acadêmicos através de encontros presenciais com a coordenadora. Foi discutida a importância de se levar em consideração a faixa etária do público alvo, bem como foi discutida a forma pela qual o material didático (composto pelos kits experimentais e jogos, bem como o material suporte) seria trabalhado. Nessa etapa, que seguiu concomitantemente com a primeira etapa, foram confeccionados kits com os materiais de baixo custo e de fácil acesso, cujos itens foram adquiridos em supermercados e farmácias, permitindo mais uma vez que os estudantes pudessem ser engajados e contribuíssem com suas ideias para a montagem de forma prática e chamativa para o público alvo.

As estratégias de ensino que foram usadas buscaram contribuir para a consolidação e complementação do ensino de Química trabalhado em turmas de segundo ano do Ensino Médio e EJA em qualquer escola, independente da mesma possuir recursos financeiros ou não.

A terceira etapa contou com reuniões com os diretores e professores das Escolas Estaduais de Bambuí, em que permitiu contemplar a exposição, exploração e explicação do projeto desenvolvido. Após a execução dessa etapa, foram definidos os locais e os horários adequados para se colocar em prática o projeto proposto.

Diante do que foi abordado, este trabalho apresenta os resultados de um jogo didático "Quente ou Frio?" que trabalhou com a temática de Termoquímica e de uma atividade experimental denominada "Solubilidade de $\mathrm{CO}_{2}$ no refrigerante- $O$ efeito da pressão" que envolveu a abordagem de solubilidade e os conceitos a ela atribuídos (Martins, 2018). Como complementação em material de suporte foi trabalhado textos de aplicação cotidiana dos conceitos químicos de solução. De modo a verificar a assimilação e consolidação do processo de ensino e aprendizagem na área de Química, após a realização da atividade experimental e a leitura dos textos complementares, os estudantes que foram divididos em grupos, responderam às atividades objetivas compostas de oito questões.

\section{Resultados e Discussão (pode ser separado ou junto) (fonte TNR 12 - alinhado esquerda)}

\subsection{Apresentação dos materiais produzidos pela equipe de extensão}

Na Figura 1 é apresentado o kit de ensino confeccionado pela equipe de extensão e que foi entregue às Escolas Estaduais de Banbuí, Minas Gerais.

Figura 1 - Kit de ensino entregue nas escolas contempladas pelo projeto de extensão

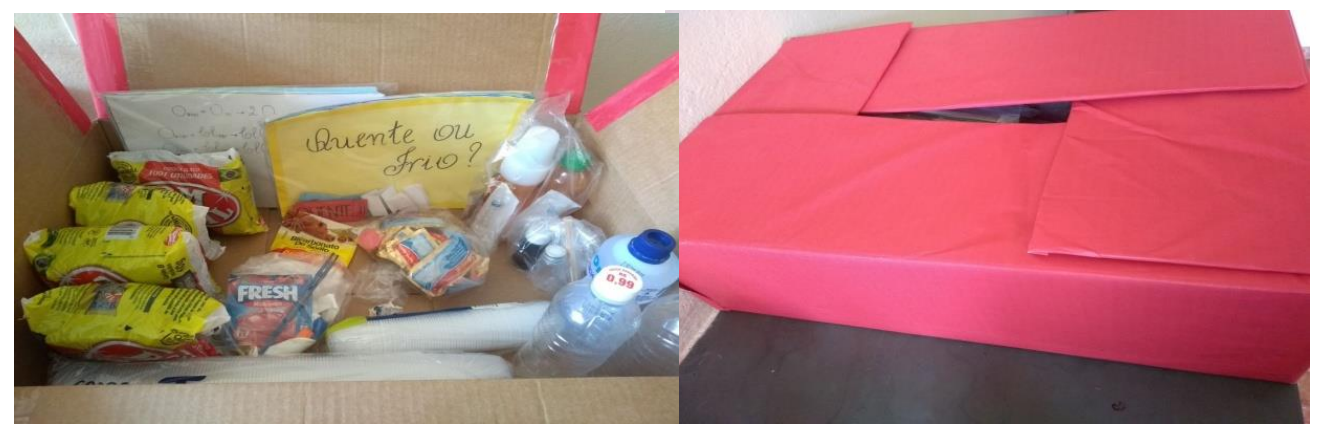

Fonte: Autores. 
Em consonância ao que é reportado na literatura e conforme pode ser verificado na Figura 1, o kit de ensino que foi produzido pela equipe envolvida no projeto de extensão contou com a utilização de materiais que podem ser facilmente encontrados em farmácias e supermercados, os quais não ofereciam riscos à saúde e danos ao meio ambiente (Sales et al., 2020).

\subsection{Análise do material produzido pela equipe de extensão}

Conforme abordagem descrita na metodologia, a reunião conduzida com um dos professores buscou verificar sua avaliação reflexiva a respeito do que tinha sido confeccionado pela equipe de extensão. Foi relatada uma avaliação positiva, já que o docente que ministrava a disciplina considerou apto a trabalhar conteúdos complementares às aulas de Química no Ensino Médio. Vale a pena reportar o papel importante do professor da Escola Estadual, uma vez que o docente não deve ser considerado objeto de trabalho, mas agente ativo, em que se busca resgatar o seu papel como sujeito do processo do conhecimento (Lima, 1996).

O docente ainda afirmou que o projeto visou fornecer um suporte pertinente a uma fixação interativa do conteúdo de química lecionado no Ensino Médio e que o material didático produzido era eficiente para atingir tal objetivo. Em suma, avaliar a qualidade de Materiais Didáticos torna-se imprescindível, ao passo que assumem um papel significativo no cotidiano das escolas, pois serão dentre outras possibilidades, instrumento norteador da prática docente, principalmente no âmbito de organização dos conteúdos explorados em cada etapa escolar, sem, no entanto, ter a pretensão de substituir a autonomia do professor (Santos et al., 2020).

Ainda de acordo com abordagens descritas na literatura, a parceria entre instituições de ensino e escolas de ensino médio através de projetos de extensão é capaz de facilitar o ensino e a aprendizagem, uma vez que a mesma permite a criação de métodos didáticos para a consolidação do conhecimento, bem como inferir outros componentes na práxis do educador como hábito de pesquisa, dentre tantos pré-requisitos para um exercício da profissão com sucesso (Cardoso et al., 2018; Santos \& Ribeiro, 2020; Santos \& Amaral, 2020).

As informações obtidas foram relevantes para o desenvolvimento do projeto, uma vez que o os recursos didáticopedagógicos foram empregados em uma etapa posterior, em que os estudantes tiveram suas atividades avaliadas tanto quantitativamente como qualitativamente.

\subsection{Avaliação do Jogo Termoquímico: “Quente ou Frio?”}

Um dos recursos empregados na consolidação do ensino do conteúdo de Termoquímica consistiu da aplicação do Jogo "Quente ou Frio?", o qual tinha por objetivo avaliar a aprendizagem dos estudantes com relação à determinação da entalpia de reação $\left(\Delta \mathrm{H}_{\mathrm{r}}\right)$ por três métodos distintos: lei de Hess, energia de ligação e entalpia de formação.

Através do cálculo das entalpias pelos três métodos distintos, os estudantes divididos em equipes deveriam relacionálas ao que aconteceria nas vizinhanças onde se processava a reação, indicando a placa "quente" se a reação liberasse energia para a vizinhança na forma de calor (processo exotérmico) ou "frio", caso a reação absorvesse energia (processo endotérmico). Vale reportar que foram recolhidas as folhas em que os estudantes das duas turmas de uma das escolas contempladas no projeto realizaram os cálculos, em que foi possível identificar as dificuldades, analisá-las e discuti-las, de modo a supri-las de forma interativa.

O jogo didático, embora fosse premiado pela equipe de extensão e pontuado pelo docente de Química da Escola Estadual, teve muita cooperação dos estudantes das turmas, sendo que os mesmos se mostraram muito interessados e esforçados em resolver as equações termoquímicas e relacioná-las com as placas: "quente" e "frio". Nesse sentido, pode-se evidenciar que a utilização do jogo didático permitiu construir o conhecimento químico com os estudantes, favorecendo o 
processo de ensino-aprendizagem. Vale ressaltar que o emprego do jogo objetivou verificar se houve ou não a aprendizagem significativa dos estudantes com relação à Termoquímica, o que por sua vez está em consonância com a literatura que prevê a utilização desses tipos de jogos no desfecho da unidade didática (Gonçalves, 2016).

$\mathrm{Na}$ Tabela 1 é apresentada uma análise do desempenho das duas turmas com relação aos métodos de determinação da entalpia de reação.

Tabela 1 - Desempenho médio das turmas de segundo ano do Ensino Médio de uma das Escolas Estaduais contempladas no projeto de extensão

\begin{tabular}{ccc}
\hline Método & Turma & Índice de acerto (\%) \\
\hline Lei de Hess & A & 100,0 \\
& B & 50,0 \\
\hline Entalpia de formação & A & 62,5 \\
& B & 25,0 \\
\hline Energia de ligação & A & 37,5 \\
& B & 50,0 \\
\hline
\end{tabular}

Fonte: Autores.

Conforme pode ser verificado na Tabela 1, a turma A apresentou maior desempenho quando foram utilizados os métodos por entalpia de formação e lei de Hess, enquanto que o método para energia de ligação foi mais satisfatório para a turma B.

Entretanto, é importante salientar que no dia em que o jogo foi aplicado, nem todos os estudantes das duas turmas estavam com seus cadernos, o que pode ter influenciado nos resultados haja vista que houve a permissão de consulta ao conteúdo que já tinha sido trabalhado pelo docente que ministrava a disciplina na escola. Ressalta-se o aproveitamento total na turma A quando foi trabalhado o método por lei de Hess, também conhecida como lei da soma de calor constante (Atkins \& Jones, 2011). Esse resultado pode estar associado ao fato de que a entalpia de uma reação pode ser simplesmente calculada através da soma algébrica de equações termoquímicas que possuam variação de entalpia conhecida. Como conseqüência dessa lei, tem-se que as equações químicas podem ser operadas como se fossem equações algébricas (Atkins \& Jones, 2011).

De maneira geral, essa é uma lei experimental (empírica) e estabelece que a variação de entalpia de uma reação química depende apenas dos estados inicial e final, uma vez que esse parâmetro termodinâmico pode ser concebido como uma função de estado (Brown et al., 2005). Nesse caso, não importa quantos passos a reação procede através, que o calor liberado ou absorvido em uma transformação química é o mesmo (Brown et al., 2005; Atkins \& Jones, 2011).

Por fim, pode-se inferir que os resultados obtidos pela turma A são considerados promissores na medida em que esse método pode ser aplicado para se calcular entalpias de reações que são difíceis de medir, desde que se tenha todos os dados das reações relacionadas. (Portal São Francisco, 2016).

Por outro lado, para a mesma turma avaliada verificou-se um baixo rendimento $(37,5 \%)$ quando se determinou a entalpia de reação empregando os valores de energia de ligação. Esse resultado pode estar associado ao fato desse método envolver uma série de etapas que vão desde o balanceamento das equações termoquímicas até a verificação do número de ligações que devem ser rompidas nos reagentes e formadas nos produtos durante a transformação. Além disso, vale salientar 
que os estudantes devem estar atentos às associações que definem os processos endotérmicos (observados na quebra de ligações químicas) e exotérmicos (verificados na formação de ligações químicas) (Brown et al., 2005; Atkins \& Jones, 2011).

Diante dos resultados apresentados, pode-se inferir que o jogo didático contribuiu como um instrumento de diagnóstico das dificuldades dos estudantes com relação à temática de ensino abordada, sendo que os resultados de sua aplicação foram posteriormente mostrados ao professor que ministrava a disciplina de Química. De modo geral, o jogo é indicado como um tipo de recurso que pode ser empregado em momentos distintos no contexto do processo de ensinoaprendizagem, sendo considerado um importante instrumento de trabalho do professor na área de Química.

É possível relatar que a aplicação do jogo atendeu aos dois objetivos: lúdico e educativo, já que além da diversão, verificou-se a compreensão de conceitos. O esforço espontâneo observado, integrando as várias dimensões do estudante, como a afetividade e o trabalho em grupo permitiu com que esse recurso pudesse ser inserido como uma sugestão para trabalhos escolares nas aulas da disciplina (Nascimento et al., 2016).

Foi ainda observado que durante o desenvolvimento do jogo os estudantes das duas turmas (A e B) apresentaram apreciável compreensão quanto ao entendimento do significado de reações endotérmicas e exotérmicas, bem como das sensações que essas reações causavam nas vizinhanças dos sistemas analisados. Tais resultados indicam que esta estratégia proporcionou aos estudantes uma forma prazerosa e divertida de estudar, além de oferecer ao professor da Escola Estadual uma maneira diferente de avaliar a assimilação dos conteúdos estudados, de revisão dos conceitos ou como um meio mais dinâmico, conforme abordagens reportadas na literatura (Nascimento et al., 2016).

\subsection{Avaliação da atividade experimental "Solubilidade do $\mathrm{CO}_{2}$ no refrigerante- efeito da pressão"}

Em outra escola foi aplicado o experimento da Solubilidade do $\mathrm{CO}_{2}$ no refrigerante, considerando o efeito da pressão. $\mathrm{O}$ delineamento experimental contou com os seguintes procedimentos: Abriu-se o frasco de refrigerante e transferir aproximadamente $50 \mathrm{~mL}$ para um copo transparente, retirou-se $10 \mathrm{~mL}$ do líquido com o auxílio de uma seringa. Com o dedo, tampou-se a ponta da seringa e puxou-se o seu êmbolo de modo a verificar o ocorrido (Martins, 2018).

Após a realização da atividade experimental, foram trabalhados textos complementares de contextualização que reportavam o efeito da pressão na solubilidade de gases no sangue ao ser realizado um mergulho e como a temperatura poderia influenciar no aquecimento global levando em consideração o mesmo eixo temático.

A fim de se avaliar quantitativamente o emprego das duas ferramentas didático-pedagógicas no processo de ensinoaprendizagem em Química, foram aplicadas atividades objetivas relacionadas ao efeito da pressão e da temperatura na solubilidade, bem como a classificação de soluções levando em consideração o coeficiente de solubilidade.

O resultado médio de desempenho das atividades que foram aplicadas no $2^{\circ}$ ano EJA da segunda Escola Estadual está apresentado na Figura 2. 
Figura 2 - Desempenho médio da turma com relação à temática de Soluções.

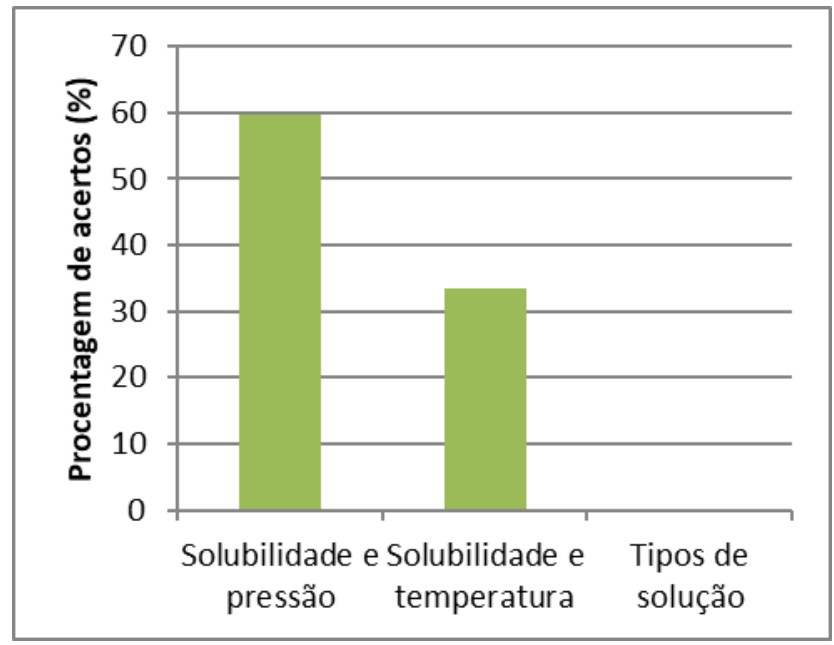

Fonte: Autores.

Pode-se observar que o efeito da pressão na solubilidade contou com um maior percentual de acertos nas atividades propostas, o que pode estar relacionado ao fato de que além do texto de contextualização, foi trabalhada a atividade experimental com os estudantes. De acordo com abordagens reportadas na literatura, no ensino de Ciências a experimentação pode ser uma estratégia eficiente para a criação de problemas reais que permitam a contextualização e o estímulo de questionamentos de investigação (Guimarães, 2009). Por outro lado, verificou-se que a classificação das soluções não apresentou rendimento, justificado pelo fato desses conceitos não serem abordados no cotidiano.

Conforme pode ser relatado, ao ensinar ciência, no âmbito escolar, é necessário nortear o que os estudantes observarão, já que o processo de ensino-aprendizagem não deve ser construído em um vazio conceitual, tampouco apetecer sobre percepções associadas à mera observação. A partir dos resultados obtidos, a equipe de extensão verificou a possibilidade de se trabalhar com a aprendizagem significativa, em que a nova informação interage com uma estrutura de conhecimentos específicos, estabelecendo as "pontes cognitivas” entre o que já sabe e o que está aprendendo (Guimarães, 2009).

\subsection{A importância do projeto segundo a percepção dos docentes e estudantes das escolas envolvidas no projeto}

De modo a validar e ratificar a importância das ferramentas didático-pedagógicas para a consolidação da aprendizagem de Química foi realizada uma investigação qualitativa vinculada às impressões dos docentes e estudantes a respeito do projeto que foi desenvolvido.

Os docentes pontuaram que a ação de extensão foi importante, na medida em que verificaram o empenho e participação ativa dos estudantes durante o seu desenvolvimento. O fenômeno observado pode estar associado ao fato de ter sido levada em consideração a aprendizagem significativa, em que o conhecimento prévio é uma condição necessária, mas não suficiente (Silva, 2020).

Os docentes ainda salientaram a respeito da transformação observada, uma vez que verificaram que a disciplina foi olhada sob uma nova perspectiva pelo fato de estar contextualizada e inserida no dia a dia. O levantamento abordado indica a relevância do projeto desenvolvido, sendo que o resultado pode ser reportado como satisfatório na medida em que permitiu a consolidação dessa Ciência.

Mais uma vez é evidenciada a aprendizagem significativa, já que de acordo com a Teoria da Aprendizagem Significativa, as três exigências relacionadas aos conhecimentos prévios do estudante; material potencial significativo 
(produzido pela equipe de extensão) e predisposição do discente em aprender o conteúdo escolar foram satisfatoriamente atendidas (Silva, 2020).

De acordo com Giffoni e colaboradores (2020), em se tratando do ensino de química, muitos estudantes não conseguem enxergar a relação entre o conteúdo e o seu cotidiano por mais que analiticamente estejam expostas tais proficiências em conteúdos atinentes à docência. Também foi destacada a importância da confecção de um material de apoio complementar em que se contemplou os conteúdos de uma forma abrangente e aplicável à fixação dos conteúdos curriculares. Nesse sentido, pode-se inferir que o material de suporte que foi entregue juntamente com os kits de ensino forneceu subsídios adequados no aprimoramento da aprendizagem dos estudantes.

De acordo com relatos descritos na literatura, o trabalho desenvolvido permitiu formular um modelo pedagógico que correlacionou os conteúdos de química com os conceitos já conhecidos pelos alunos (Giffoni et al., 2020).

De acordo com um professor de uma das escolas envolvidas, "O público atendido teve um impacto positivo e de alta relevância na vida social e estudantil, pois, com as aulas práticas puderam ver a importância dos conteúdos de química do ensino médio no cotidiano, além de aprender e fixar o conteúdo de forma lúdica".

Foi também ressaltada a importância do projeto para os estudantes, indicando que a disciplina de Química pode ser ministrada por meio de estratégias diferenciadas que busquem a consolidação de seu ensino. Nesse contexto, os conteúdos da disciplina de Química puderam ser mudados e ampliados, realizando uma aprendizagem significativa relacionada com as questões de responsabilidade social e aplicações cotidianas (Giffoni et al., 2020).

Foram ainda buscadas opiniões com os estudantes das escolas nas quais o trabalho foi desenvolvido, levando em consideração as metodologias de ensino que foram empregadas. Um dos estudantes indicou que as experiências foram interessantes para o seu entendimento, sendo que o material de suporte que foi produzido pela equipe de extensão atuou de maneira adequada na elucidação e fixação dos conteúdos ministrados na disciplina.

$\mathrm{O}$ êxito nos resultados obtidos pelo desenvolvimento da atividade experimental pode estar vinculado à utilização de materiais facilmente encontrados no dia a dia. De acordo com a literatura disponível, quanto maior for a simplicidade de execução e mais conhecidos forem os materiais utilizados pelo estudante, maior será a compreensão das ideias que a atividade experimental pode proporcionar (Sales et al., 2020).

Outro estudante revela a importância do jogo para a consolidação do aprendizado, pois de acordo com o mesmo, a aplicação do jogo termoquímico "Quente ou Frio?" permitiu com que ele tivesse maior apreensão da disciplina, além de permitir tirar dúvidas a respeito dela. Em consonância com outros trabalhos dispostos na literatura, o jogo com finalidades educativas apresenta a característica de ser um meio integrador, onde os participantes têm a chance de debater e conversar com o exposto (Nascimento et al., 2016).

Vale ressaltar que o jogo não deve ser utilizado ao acaso, mas visto como uma das atividades dentro de uma sequência definida de aprendizagens e um meio a ser usado para se alcançar determinados objetivos educacionais (Nascimento et al., 2016). No caso do presente trabalho, "Quente ou Frio?" foi empregado com a finalidade de diagnosticar as dificuldades e analisar comparativamente os métodos empregados na determinação da entalpia de reação.

\subsection{A percep̧̧ão do projeto segundo a equipe de extensão}

Após o desenvolvimento do projeto, a coordenadora aplicou um questionário de natureza qualitativa aos estudantes que compunham a equipe de extensão com a finalidade de verificar os efeitos multiplicadores referentes ao seu desenvolvimento. A seguir são apresentadas as perguntas e as respostas elaboradas pelos envolvidos. 
1- Qual foi a contribuição do projeto para a formação cidadã e acadêmica de vocês?

Respostas: "O projeto teve intensa contribuição na minha formação acadêmica, pude perceber os desafios de um professor ao lecionar. As tomadas de decisão dentro da sala de aula por vezes exigem rapidez e profissionalismo".

"Contribuições de inúmeras formas, que incluem: participação em reuniões de planejamento, contato com a atividade de lecionar, desenvolvimento e aprimoramento de habilidades, acúmulo de conhecimentos, entre outros".

2- Quais foram as maiores dificuldades? Quais os aspectos mais relevantes?

Respostas: "Um dos maiores desafios enfrentados foi quanto à mudança de perspectiva dos alunos em relação à disciplina, uma vez que houve uma resistência muito grande, que a cada dia de prática que se passava os conceitos de Química que eram trabalhados foram desmistificados através da interação com as estratégias adotadas. E quando esse objetivo foi alcançado tornou possivel promover um engajamento maior dos alunos impactando os resultados".

"Ao meu vir, uma se destacou: fazer com que os alunos prestem atenção e evitem conversas na hora da explicação. Já os aspectos relevantes com certeza englobam os resultados, bem como o aprendizado mútuo de forma diferente. O fato de poder levar isso a uma sala de aula e apresentar para a nossa Instituição".

Conforme pode ser analisado nas respostas dos questionários, o desenvolvimento do projeto foi algo que precisou de envolvimento, comprometimento e dedicação dos estudantes uma vez que foram configurados os desafios de se lecionar em sala de aula. Porém é notório perceber a relevância do emprego de diferentes ferramentas didático- pedagógicas vinculadas à consolidação da Química no Ensino Médio.

De acordo com a Teoria Kellyana (1963), puderam ser avaliadas e verificadas etapas vinculadas ao processo de aprendizagem. O ciclo se iniciou com a etapa da Antecipação, momento em que os estudantes se reuniram com a coordenadora do projeto, sendo-lhes informados os conteúdos que seriam trabalhados nas Escolas Estaduais contempladas pelo projeto de ensino. Em seguida, os mesmos foram engajados na etapa do Investimento, momento em que puderam contribuir para a melhoria da qualidade do trabalho. Nessa etapa os estudantes puderam apresentar o que tinha sido solicitado pela orientadora do projeto, sendo então discutidas as maneiras mais adequadas de se trabalhar com diferentes ferramentas didáticopedagógicas. A etapa do Encontro foi avaliada durante o desenvolvimento do projeto nas escolas, momento em que foi possível realizar análises quantitativas e qualitativas vinculadas aos impactos do projeto. Na quarta etapa, de Confirmação ou Desconfirmação, a equipe de extensão avaliou os impactos do projeto para os estudantes e docentes das escolas envolvidas. Por fim, a etapa da Revisão Construtiva foi verificada na avaliação da percepção dos estudantes que compunham a equipe de extensão, em que foi possível ressignificar o ato de educar (Kelly, 1963).

\section{Considerações Finais}

De modo geral, a Química é considerada como uma disciplina que não desperta o interesse dos estudantes, o que incentiva a busca por estratégias de ensino atraentes e motivadoras. Os recursos didático-pedagógicos utilizados no presente trabalho apresentaram resultados satisfatórios, já que além de permitir o diagnóstico das deficiências com relação às temáticas envolvidas serviu como elementos norteadores para a validação de uma aprendizagem significativa.

O jogo trabalhado nas duas turmas de uma das escolas contempladas pela ação extensionista evidenciou a importância do lúdico no ensino, pois apesar dos resultados de rendimento não serem ideais, contaram com uma avaliação positiva do público-alvo constituído pelo docente e estudantes. $\mathrm{O}$ interesse foi notoriamente observado pela equipe de extensão.

Por outro lado, verificou-se que a atividade experimental contribuiu como um recurso fundamental para a assimilação de conteúdos relacionados à influência da pressão na solubilidade de gases em líquidos. Para a equipe integradora do projeto, a 
experiência proporcionada permitiu vivenciar conteúdos de ensino médio de uma maneira distinta a que tiveram contato, permitindo-lhes observar defasagens inerentes ao ensino.

As explicações dos conteúdos e a condução dos jogos didáticos e atividades experimentais tornaram os estudantes da equipe de extensão construtores do processo de ensino-aprendizagem em uma experiência única. Acredita-se que para trabalhos futuros sejam buscadas outras temáticas vinculadas a esses recursos didático-pedagógicos que foram satisfatoriamente utilizados no processo de ensino-aprendizagem significativo.

\section{Agradecimentos}

Os autores agradecem à Coordenadoria de Extensão do IFMG- Campus Bambuí e às diretorias das Escolas Estaduais nas quais o Projeto de Extensão foi aplicado.

\section{Referências}

Afonso, A. F., Delfino, C. O. \& Pires, H. S. (2019). Termoquiz: Construindo o conhecimento por meio do Jogo didático. Revista de Iniciação à Docência, 3(2), 32-41.

Arroio, A., Honório, K. M., Weber, K. C., Homem-de-mello, P., Gambardella, M. T. P. \& da Silva, A. B. F. (2006). O show da química: motivando o interesse científico. Química Nova, 29 (1), 173-178.

Atkins, P. \& Jones, L. (2011). Princípios de Química: Questionando a Vida Moderna e o Meio Ambiente. (5a ed.), Bookman.

Brown, T. L., Lemay, H. E. \& Bursten, B. E. (2005). Química: A ciência central. (9a ed.), Pearson Education.

Cardoso, P. H. G., Santos, L. C. dos, Silva, V. C. \& Amorim, C. M. F. G. (2018). Impacto das aulas práticas no laboratório de química no ensino médio. Resumos do V Congresso Nacional de Educação, V, Olinda, Brasil.

Cruz, N., Souza K. G. \& Sousa F. J. (2014). Análise e desenvolvimento de kits experimentais de baixo custo e fácil acesso para o ensino de química. Resumos do XVII Encontro Nacional de Ensino de Química, XVII, Ouro Preto, Brasil.

Cunha, M. B. (2004). Jogos de Química: Desenvolvendo habilidades e socializando o grupo. Resumos do XII Encontro Nacional de Ensino de Química, XII, Goiânia, Brasil.

Giffoni, J. S., Barroso, M. C. S. \& Sampaio, C. G. (2020). Aprendizagem significativa no ensino de Química: uma abordagem ciência, tecnologia e sociedade. Research, Society and Development, 9(6), 1-14.

Gonçalves, C. A. A. (2016). Calorias dos alimentos: uma abordagem temática e lúdica para o ensino de termoquímica. Dissertação de Mestrado em Ensino de Ciências, Universidade Federal de Ouro Preto, Ouro Preto, Minas Gerais, Brasil.

Guimarães, C. C. (2009). Experimentação no ensino de química: caminhos e descaminhos rumo à aprendizagem significativa. Química nova na escola, 31 (3), 198-202.

Kelly, G. A. (1963). A theory of personality: the psychology of personal constructs. New York: W. W. Norton.

Lima, E. C., Mariano, D. G., Pavan, F. M., Lima, A. A. \& Açari, D. P. (2018). Uso de Jogos Lúdicos Como Auxílio Para o Ensino de Química. https//www.unifia.edu.br.

Lima, M. E. C. C. (1996). Formação continuada de professores de química. Química Nova na Escola, 4, 1-6.

Lima, R. A. \& Benarrosh, P. F. P. M. (2010). A utilização de textos complementares para o ensino de Química: Uma abordagem multidisciplinar. Resumos do $8^{\circ}$ Simpósio Brasileiro de Educação Química, Natal, Brasil.

Martins, M. (2016). Solubilidade de $\mathrm{CO}_{2}$ no refrigerante. https://www.youtube.com/watch?v=mJvXCiFlcpk.

Nascimento, A. M. da S., da Silva, M. C., Ferreira, J. A. \& de Lira, M. M. R. (2016). Trilha da termoquímica: um jogo didático como facilitador do processo de ensino. Resumos do III Congresso Internacional das Licenciaturas, Brasil.

Oliveira, F. L. B., Silva, J. M., Valença, L. L. S., Freire, J. G. \& Costa, L. S. (2010). A prática pedagógica do ensino de ciências nas escolas públicas de Santa Cruz. Holos, 26 (5), 218-226.

Pereira, A. S., Shitsuka, D. M., Parreira, F. J. \& Shitsuka, R. (2018). Metodologia da pesquisa científica. Ed. UAB/NTE/UFSM. https://repositorio.ufsm.br/bitstream/handle/1/15824/Lic_Computacao_Metodologia-Pesquisa-Cientifica.pdf?sequence=1 .

Portal São Francisco (2016). Lei de Hess. portalsaofrancisco.com.br.

Sales, P. F.de, de Araújo, R. L. \& Pereira, R. A. (2020). Química acessível para crianças. Research, Society and Development, 9 (8), 1-20. 
Santos, F. R. dos \& Amaral, C. L. C. (2020). A química forense como tema contextualizador no ensino de química. Research, Society and Development, 9 (3), 1-15.

Santos, M. I. A. \& Ribeiro, A. P. M. (2020). O ensino-aprendizagem na educação de jovens e adultos e a teoria da reprodução de Bourdieu. Research, Society and Development, $9(3), 1-15$.

Santos, V. C., Cardoso, P. H. G., Guedes, F. N., Lima, M. D. C., \& Amorim, C. M. C. (2020). Didáticas experimentais como ferramenta de ensino as aulas de química no ensino médio. Research, Society and Development, 9(7), 1-16.

Silva, J. B. (2020). A Teoria da Aprendizagem Significativa de David Ausubel: uma análise das condições necessárias. Research, Society and Development, $9(3), 1-13$.

Soares, M. H. F. B., \& Cavalheiro, E. T. G. (2016). O ludo como um jogo para discutir conceitos em termoquímica. Química Nova na Escola, $23,27-31$.

Sousa, A. S., Silva, A. S., Araújo, D. S., Costa, E. O., Lima, J. A. C., Araújo, M. L. M., Lima, R. C. S., \& Santos, J. C. O. (2014). A experimentação usando material de baixo custo no ensino da química para alunos do $1^{\circ}$ ano do ensino médio. Resumos do LIV Congresso Brasileiro de Química, LIV, Natal, Brasil. 